\title{
Preparation and Electrochemical Properties of Porous Carbon Materials Derived from Waste Plastic Foam and Their Application for Supercapacitors
}

He Zhu, Songhong Fan, Zhishang Gao, Zhangzhang Tang, Zhong Ren, Mingjian Zhang, Huixia Feng, Heming Luo ${ }^{*}$, Jianqiang Zhang ${ }^{*}$

School of Petrochemical Engineering, Lan Zhou University of Technology, Lanzhou 730050, China *E-mail: luohm666@163.com, zhangjq@lut.edu.cn

doi: $10.20964 / 2021.03 .59$

Received: 29 November 2020 / Accepted: 12 January 2021 / Published: 31 January 2021

In order to achieve resource recycling and environmental protection, the waste plastic foam-based porous carbon material PMC-T is prepared by a high-temperature pyrolysis activation method. Plastic foambased porous carbon PMC-T is an amorphous carbon with a honeycomb-like structure, a specific surface area of up to $2281 \mathrm{~m}^{2} \mathrm{~g}^{-1}$, and a reasonable pore size distribution. Cyclic voltammetry tests and galvanostatic charge/discharge tests show that the plastic foam-based porous carbon material PMC-700 exhibits excellent electrochemical performance. Specifically, in a $6 \mathrm{M} \mathrm{KOH}$ electrolyte at a $1 \mathrm{~A} \mathrm{~g}^{-1}$ current density, the specific capacitance reached $296 \mathrm{~F} \mathrm{~g}^{-1}$. Additionally, PMC-T demonstrates good cycle stability, and after 5000 charging and discharging cycles, its capacitance retention rate is as high as $87.1 \%$. The plastic foam-based porous carbon exhibits excellent electrochemical properties.

Keywords: Waste plastic foam; Porous carbon material; Supercapacitor; Specific surface area; Electrochemical performance

\section{$\underline{\text { FULL TEXT }}$}

(C) 2021 The Authors. Published by ESG (www.electrochemsci.org). This article is an open access article distributed under the terms and conditions of the Creative Commons Attribution license (http://creativecommons.org/licenses/by/4.0/). 